\title{
Identidad y naturaleza de la asignatura de Religión en las enseñanzas obligatorias del sistema educativo español del siglo XXI"
}

\author{
Rafael González Martín**
}

Recepción: 10 de diciembre de 2017 • Aprobación: 21 de enero de 2018

\section{Resumen}

La religión ha sido desde décadas un elemento esencial en la enseñanza y en la formación de los distintos sistemas educativos españoles y de países europeos, pues ha sido considerada como un pilar básico en el bagaje cultural y social de cada país, como un instrumento de vital importancia en la transmisión de valores. Por ese motivo, no debemos dejar de ser conscientes del papel tan relevante que la religión ocupa en la sociedad, ya que esta marca y orienta los modelos y las formas de vida de la mayoría de los ciudadanos.

Palabras clave: escuela, enseñanza, religión, sociedad.

* Trabajo investigativo realizado en el programa para la Declaración Eclesiástica de Competencia Académica (DECA) en el Centro Universitario La Salle, de Madrid. Citar como: González Martín, R. (2018). Identidad y naturaleza de la asignatura de Religión en las enseñanzas obligatorias del sistema educativo español del siglo XXI. Revista Albertus Magnus, IX(1), 109-129. Doi: https://doi.org/10.15332/s2011-9771.2018.0001.05

* Colegio María Auxiliadora, España. Correo electrónico: rafael.gonzalez@salesianas.org 


\title{
Identity and nature of the subject of religion in the compulsory education of the 21st century Spanish education system
}

\begin{abstract}
For decades, religion has been an essential element in the teaching and training of the different Spanish and European educational systems, since it has been considered as a basic pillar in the cultural and social background of each country as a vital instrument in the transmission of values. For this reason, we must not be aware of the important role that religion occupies in society, since it marks and guides the models and ways of life of the majority of citizens.
\end{abstract}

Keywords: school, teaching, religion; society.

\section{Identidade e natureza do tema da religião na escolaridade obrigatória do sistema educativo espanhol do século XXI}

\section{Resumo}

Durante décadas, a religião tem sido um elemento essencial no ensino e na formação dos diferentes sistemas educacionais espanhóis e europeus, uma vez que foi considerado um pilar básico no contexto cultural e social de cada país como um instrumento vital em a transmissão de valores. Por esta razão, não devemos estar conscientes do papel importante que a religião ocupa na sociedade, pois marca e orienta os modelos e modos de vida da maioria dos cidadãos.

Palavras-chave: escola, ensino, religião, sociedade.

\section{Introducción}

La sociedad precisa cada vez más de personas que posean nuevas competencias, que sean creativas, innovadoras, reflexivas, críticas; ciudadanos con espíritu crítico capaces de existir en la incertidumbre social en la que vivimos. La educación, como parte integrante de esa estructura social, es la valedora de crear 
esas personas, desde la formación integral de estas. Ahora bien, la persona se ve expuesta a los cambios que se producen en la evolución del pensamiento de la misma sociedad y como consecuencia de los cambios generados por los intereses políticos y sociales del momento.

Así, en los últimos veinticinco años del pasado siglo XX y en la primera década del siglo XXI, la política educativa ha dado lugar a varias leyes: Ley General de Educación y Financiamiento de la Reforma Educativa (LGE) de 4 de agosto de 1970; Ley Orgánica 8/1985, de 3 de julio, reguladora del Derecho a la Educación; la Ley Orgánica 1/1990, de 3 de octubre, de Ordenación General del Sistema Educativo; Ley Orgánica 10/2002, de 23 de diciembre, de Calidad de la Educación; Ley Orgánica 2/2006, de 3 de mayo, de Educación; y Ley Orgánica 8/2013, de 9 de diciembre, para la mejora de la calidad educativa, que posiblemente no han estado sustentadas en el bien común por medio del diálogo, sino en la confrontación y aniquilación del adversario. Pues algo parecido ha ocurrido con la enseñanza religiosa en el sistema educativo español dentro de las enseñanzas obligatorias establecidas en las distintas leyes.

La enseñanza de la religión en el sistema educativo español tiene su base en la Constitución española de 1978 (arts. 27.3 y 16.3) y en el acuerdo entre el Estado español y la Santa Sede sobre enseñanza y asuntos culturales de 1979, que fue elaborado por un gobierno democrático y que forma parte del ordenamiento jurídico español. España siempre ha contado con una tradición educativa en la cual el hecho religioso ha estado presente de forma permanente. Así podemos comprobarlo en las principales leyes y órdenes educativas (Panizo y Arce, 2012; Yzaguirre, 2002). Al igual que en España, en la mayoría de los países de Europa, la enseñanza religiosa se fundamenta en la propia Constitución de cada nación. Tal es el caso de Alemania, Austria, Bélgica, Dinamarca, España, Finlandia, Grecia, Irlanda, Italia, Luxemburgo, Portugal y Suecia, donde se reconoce la formación religiosa dentro del sistema educativo. Francia es el único país de la Unión Europea (UE) que sitúa esta educación fuera del ámbito escolar.

En Alemania, se imparten clases de religión, tanto en escuelas públicas como privadas, en primaria y secundaria. La base legal de la educación religiosa se fundamenta en la Constitución (o Ley Fundamental) de 1949. Modificada el 31 de agosto de 1999, garantiza a toda la población la libertad de creencias y profesión religiosa e ideológica, así como el ejercicio del culto. La enseñanza de la religión forma parte del plan de estudios y es obligatoria salvo a petición de exención (la alternativa varía según el land), y va desde filosofía hasta el estudio libre.

En Austria, la asignatura es impartida en escuelas públicas y privadas. En la Constitución Federal del país de 1920, se dictamina en el artículo 14.a que será 
competencia federal la legislación y competencia regional de la ejecución en materia de enseñanza religiosa. Las escuelas austriacas deben ofrecer obligatoriamente formación religiosa. De acuerdo con la ley sobre educación religiosa de los niños, los padres tienen el derecho de decidir en este tipo de formación para sus hijos si estos son menores de 14 años. En el caso de superar tal edad, son ellos mismos los que pueden optar por esta formación.

En Bélgica, existe una asignatura de religión confesional, así como una asignatura de humanismo laico. En lo que respecta específicamente a la educación religiosa, se fundamenta en un pacto escolar firmado en 1959 para evitar los litigios entre el Estado y los católicos en materia de enseñanza.

En Finlandia, el país europeo más envidiado por su nivel educativo (según el informe PISA 2015), se estudia religión como una asignatura más, obligatoria en los cursos que se corresponden con la primaria y la secundaria española y, como tal, cuenta para la media académica como las demás. Tiene una asignatura de ética como alternativa y a elección de los padres.

En Francia, la asignatura de Religión fue desterrada de la enseñanza pública en marzo de 1882. En 2002, el Gobierno socialista de Lionel Jospin encargó un informe para volver a pensar el posible puesto de la enseñanza de la religión en la escuela pública. Aquel informe aconsejaba la enseñanza del hecho religioso en la escuela pública y afirmaba el autor de dicho informe que "el olvido e ignorancia de la religión podía tener consecuencias catastróficas para la cultura en general y la memoria colectiva" (Víboras, 2014). Un decreto de julio de 2006 reintrodujo la enseñanza del hecho religioso en la escuela pública francesa, intentando ofrecer a los alumnos una "base común" de conocimientos históricos y religiosos. La asignatura iba a comenzar a impartirse en 2012, pero su aplicación se suspendió con la llegada al Elíseo de François Hollande.

Por su parte, en Holanda la educación religiosa se imparte únicamente en escuelas confesionales, según la Constitución de 1983, la Ley de Enseñanza Básica y la Ley Mamut. Cualquier particular o comunidad puede fundar una escuela con la orientación religiosa que quiera o sobre principios laicos. Estas llamadas escuelas especiales, que constituyen más de las tres cuartas partes de los centros educativos, son supervisadas y subvencionadas íntegramente por el Estado, al igual que las escuelas públicas fundadas por el Estado y gestionadas por los ayuntamientos, que suponen menos de la cuarta parte del total. Todas las escuelas están obligadas a impartir una asignatura de ética, que debe incluir conocimientos sobre la mayoría de las religiones.

En Irlanda, la educación confesional está incluida en el currículo de la educación obligatoria, según la Constitución de 1937, pero los estudiantes, en forma 
individual, podrán desistir de dicha educación, aunque el objetivo curricular es proporcionar educación religiosa, moral y secular a los alumnos. En Italia, según la Constitución de 1947 y en los acuerdos con la Santa Sede de 1984, existe un currículo nacional establecido por ley para la educación de nivel obligatorio, y todas las escuelas deben ofrecer educación confesional. Se imparte en todas las escuelas. En Portugal, el fundamento legal en que se basa la enseñanza de la religión se basa en la Constitución de 1976 y en el Decreto de enseñanza moral y religiosa de 1998. La asignatura es de libre elección por parte de los alumnos, pero de oferta obligatoria por los centros.

Las escuelas públicas británicas (Reino Unido), según Education Act de 1944 (la de 1980 en Escocia), tienen que ofrecer la asignatura de Religión en primaria y en secundaria obligatoria (de los 5 a los 16 años). Si los padres no quieren que sus hijos cursen la asignatura, estos quedan exentos, ya que no existe ninguna materia alternativa. La asignatura de Religión no forma parte del núcleo de asignaturas básicas como Lengua o Matemáticas y no se incluye en los exámenes oficiales que cada alumno debe superar.

En Suecia, según la Constitución de 1974, la asignatura de Religión es obligatoria en todas las escuelas, sin alternativa. La educación confesional generalmente se ofrece en escuelas que reciben algún tipo de subsidio del sector privado, con frecuencia de un organismo de carácter religioso, si bien existe la posibilidad de acceder a una asignatura de religión confesional en los colegios públicos.

\section{Identidad y naturaleza de la asignatura de Religión en las enseñanzas obligatorias del sistema educativo español del siglo XXI}

Uno de los temas más controvertidos en el mundo de la política desde que se estableció la democracia es la presencia de la enseñanza religiosa en el currículo escolar de las enseñanzas obligatorias en España. En la actualidad, ha sido suscitado nuevamente este debate, por la aparición de la Resolución de 11 de febrero de 2015, de la Dirección General de Evaluación y Cooperación Territorial, por la que se publica el currículo de la enseñanza de Religión Católica de la Educación Primaria y de la Educación Secundaria Obligatoria, que trata el nuevo currículo de la asignatura de Religión dentro de la última reforma del sistema educativo de España, la denominada Ley Orgánica 8/2013, de 9 de diciembre, para la mejora de la calidad educativa. Y cómo no, por la instrumentalización que hacen del 
asunto algunos partidos políticos que abogan por lo que ellos llaman la escuela laica (Cano, 2014).

La cuestión de fondo se encuentra en la dificultad que tienen algunas personas y partidos políticos para comprender la diferencia que existe entre laicidad y laicismo, entre Estado democrático laico y aconfesional y Estado laicista. La laicidad de una sociedad democrática no es una ideología más entre otras, sino la expresión de la neutralidad del Estado en referencia a todas las cosmovisiones, que hacen posible la libertad ideológica, política, cultural y moral - que no ética - de todo el amplio espectro social que configura un Estado moderno democrático y, por tanto, plural. El laicismo, en cuanto pretende la anulación de algunas de las cosmovisiones que forman parte de ese Estado (es el caso de la intención de convertir en instancia privada a la religión, sacándola de la vida pública), se transforma en ideología y, si es combativo y excluyente, deviene fundamentalismo y totalitarismo (Esteban, 2015b, p. 34).

El Estado democrático laico, y por tanto aconfesional, es neutral pero no neutro. Es desde esta premisa desde donde se ha de debatir la presencia o no de la enseñanza de la religión católica en el ámbito de la escuela. Hoy son muchas las familias que en España desean que sus hijos reciban una educación fundamentada en una cosmovisión cristiana de la vida; se habla del 60 \% de la población escolar.

Los actuales acuerdos Iglesia y Estado se sustentan, precisamente, en ese interés público que suscita tal demanda, y en la respuesta que da dicha asignatura a una planificación curricular atenta al concepto moderno de educación integral y forma constructivista basada en la premisa de que toda persona encuentra su identidad y el significado y sentido de su vida a través de nexos con la comunidad, el mundo natural y los valores como la compasión y la paz. La religión es un hecho cultural que exige su tratamiento escolar si no queremos que nuestros niños y jóvenes en un futuro no sepan interpretar los fundamentos de una cultura que, se quiera o no, se ha forjado desde las claves de una cosmovisión cristiana (Esteban, 2015a).

\section{La presencia de la enseñanza religiosa en la escuela}

La presencia de la enseñanza religiosa en la escuela responde, en primer lugar, a la importancia que esta asignatura tiene dentro de la educación para que el alumno pueda conseguir un desarrollo pleno e integral de su personalidad. La necesidad de sentido del ser humano es una evidencia a la que la escuela necesariamente debe dar respuesta. La educación de la dimensión religiosa es parte fundamental para la maduración de la persona. No podría existir una formación 
integral y, por tanto, una educación de calidad, si no se permitiese el desarrollo de todas las dimensiones inherentes al ser humano, entre las cuales se encuentra la religiosa. Esta capacidad básica de la persona adquiere su auténtico cumplimiento cuando se descubre el sentido de la vida. La enseñanza de la religión católica en los centros escolares ayudará a los estudiantes a ensanchar los espacios de la racionalidad y adoptar una actitud de apertura al sentido religioso de la vida, sea cual sea su manifestación concreta (Resolución de 11 de febrero de 2015, de la Dirección General de Evaluación y Cooperación Territorial, por la que se publica el currículo de la enseñanza de Religión Católica de la Educación Primaria y de la Educación Secundaria Obligatoria).

La formación religiosa y moral católica cuenta con una larga tradición en el sistema educativo español y responde a razones profundas de la institución escolar y a derechos reconocidos en la Declaración Universal de los Derechos Humanos de 1948, que reconoce la libertad religiosa de personas y pueblos, y por la Constitución española que, no solo acepta la libertad religiosa, sino que también garantiza "el derecho que asiste a los padres para que sus hijos reciban la formación religiosa y moral que esté de acuerdo con sus convicciones", en el artículo 27.3. Esta formación está garantizada por el Acuerdo entre el Estado español y la Santa Sede sobre enseñanza y asuntos culturales, firmado el 3 de enero de 1979, en el cual se establecen los principios que hacen posible las garantías constitucionales (Resolución de 11 de febrero de 2015, de la Dirección General de Evaluación y Cooperación Territorial, por la que se publica el currículo de la enseñanza de Religión Católica de la Educación Primaria y de la Educación Secundaria Obligatoria).

La Ley Orgánica 8/2013, de 9 de diciembre, para la mejora de la calidad educativa, confiere a la enseñanza de las religiones el tratamiento académico, en educación primaria, secundaria y bachillerato, que les corresponde por su importancia para el logro de la educación integral del alumno, conforme a lo previsto en la Constitución española (art. 27.2 y 3) y en los acuerdos suscritos por el Estado español (Resolución de 11 de febrero de 2015, de la Dirección General de Evaluación y Cooperación Territorial, por la que se publica el currículo de la enseñanza de Religión Católica de la Educación Primaria y de la Educación Secundaria Obligatoria).

La disposición adicional segunda responde al derecho de los padres a la formación religiosa y moral de sus hijos, según sus convicciones, estableciendo que la religión católica se incluirá como área o materia en los niveles educativos que corresponda, que será de oferta obligatoria para los centros y de carácter voluntario para los alumnos. Asimismo, en el apartado de dicha disposición, se establece 
que, en cuanto a su presencia curricular y condiciones académicas, corresponde a la jerarquía eclesiástica determinar el currículo propio de la enseñanza religiosa católica (Resolución de 11 de febrero de 2015, de la Dirección General de Evaluación y Cooperación Territorial, por la que se publica el currículo de la enseñanza de Religión Católica de la Educación Primaria y de la Educación Secundaria Obligatoria).

\section{La Ley Orgánica $8 / 2013$, de 9 de diciembre, para la mejora de la calidad educativa y la educación religiosa}

La Ley Orgánica 8/2013, de 9 de diciembre, para la mejora de la calidad educativa es la cuarta reforma global de la estructura del sistema educativo desde la Ley General de Educación y Financiamiento de la Reforma Educativa (LGE) de 4 de agosto de 1970. Modifica la Ley Orgánica 2/2006, de 3 de mayo, de Educación.

La Ley Orgánica 8/2013, de 9 de diciembre mantiene la asignatura de Religión en la estructura de las diversas etapas educativas y se remite para su legitimidad a los acuerdos del Estado español con las diversas confesiones religiosas: la Iglesia católica (acuerdos de 3 de enero de 1979), las Iglesias evangélicas (Ley 24/1992, de 10 de noviembre, por la que se aprueba el Acuerdo de Cooperación del Estado con la Federación de Entidades Religiosas Evangélicas de España), las comunidades judías (Ley 25/1992, de 10 de noviembre, por la que se aprueba el Acuerdo de Cooperación del Estado con la Federación de Comunidades Israelitas de España) y las comunidades musulmanas (Ley 26/1992, de 10 de noviembre, por la que se aprueba el Acuerdo de Cooperación del Estado con la Comisión Islámica de España). ${ }^{1}$ Igual que en la Ley Orgánica 8/2013, de 9 de diciembre, sigue siendo una asignatura de oferta obligatoria para los centros, y voluntaria para el alumnado.

Los principales cambios con respecto a la asignatura de Religión, de la Ley Orgánica 2/2006, de 3 de mayo a la Ley Orgánica 8/2013, de 9 de diciembre son los siguientes:

1 Existe una diferencia fundamental entre los acuerdos celebrados por el Estado español con la Santa Sede y los acuerdos de cooperación celebrados por el Estado español con evangélicos, judíos y musulmanes: los primeros son equiparados a tratados internacionales, mientras que los segundos tienen la consideración de leyes de las Cortes Generales. 
- Aparece mencionada en los artículos que establecen la organización de las distintas etapas educativas (en concreto, se menciona en educación primaria [EP], educación secundaria obligatoria [ESO] y bachillerato). En las últimas leyes de educación, su regulación se establecía en las disposiciones adicionales.

- En la organización de las distintas etapas educativas, esta asignatura forma parte del grupo de las denominadas específicas (otros grupos son las troncales y las de libre configuración autonómica).

- En el grupo de asignaturas específicas, y en todos los cursos de las etapas de EP y de ESO, el alumno elegirá entre la de Religión y la de Valores Sociales y Cívicos (en EP), y entre la de Religión y la de Valores Éticos (en ESO), elección que puede modificar en los distintos cursos.

- En ese grupo de asignaturas específicas, el alumno, además de cursar obligatoriamente la de educación física y la de religión o su alternativa, debe cursar también al menos otra, a elegir entre varias, y entre las que se encuentra, de nuevo, la de religión, si es que no la hubiera elegido inicialmente como primera opción. De esta forma, no se priva a ningún alumno de la posibilidad de cursar ambas asignaturas, es decir, en educación primaria es posible que un mismo alumno curse religión y valores sociales y cívicos; y en educación secundaria obligatoria, religión y valores éticos.

- Las asignaturas de religión y su alternativa tienen la misma consideración académica y se evalúan como el resto de asignaturas, sean del grupo de troncales, específicas o de libre configuración autonómica.

- En ESO, etapa en la que los alumnos realizarán una prueba de evaluación final para la obtención del título de graduado, ni la asignatura de Religión ni su alternativa serán objeto de dicha evaluación.

- Se introduce en la definición de currículo (Ley Orgánica 8/1985, de 3 de julio, reguladora del Derecho a la Educación, art. 6) un nuevo elemento: los estándares de aprendizaje evaluables.

- $\quad$ En la Ley Orgánica 8/1985, de 3 de julio, reguladora del Derecho a la Educación, con el objetivo de mejorar la calidad de la enseñanza, se apunta a un cambio metodológico que exige una modificación radical del planteamiento a la hora de programar-evaluar. Aunque no se menciona expresamente, este cambio afectará también a la asignatura de Religión.

Junto con estas novedades, se mantienen algunos elementos que ya estaban presentes en la Ley Orgánica 2/2006, de 3 de mayo, de Educación. Así, corresponderá a la autoridad religiosa la determinación del currículo y de los estándares de 
aprendizaje evaluables que permitan la comprobación del logro de los objetivos y de la adquisición de las competencias correspondientes a la asignatura de Religión. También se mantiene lo relativo al profesorado que imparte esta asignatura, recogido en la disposición adicional tercera de la Ley Orgánica 2/2006, de 3 de mayo, de Educación; téngase en cuenta que la Ley Orgánica 8/2013, de 9 de diciembre, para la mejora de la calidad educativa es una modificación parcial de esta, entonces continúa vigente (Esteban, 2015b).

Cuestiones pendientes de concreción: la Ley Orgánica 8/2013, de 9 de diciembre, para la mejora de la calidad educativa establece que las comunidades autónomas serán las que fijen el horario de las asignaturas específicas, así como sus contenidos (aunque no sea el caso de la de Religión), de forma que podemos encontrarnos con variaciones en su carga horaria dependiendo de las distintas comunidades. Otra cuestión por concretar es cómo se entiende la evaluación de la asignatura de Religión y su alternativa. Sí sabemos que quedará excluida de las evaluaciones de etapa y de las evaluaciones externas. No queda clara la presencia de la asignatura y su alternativa en bachillerato.

\section{Currículo, Ley Orgánica $8 / 2013$, de 9 de diciembre, para la mejora de la calidad educativa de religión y moral católica en la educación secundaria obligatoria}

El acuerdo entre el Estado español y la Santa Sede sobre Enseñanza y asuntos culturales garantiza que el alumnado de la educación primaria y secundaria obligatoria que así lo solicite tiene derecho a recibir enseñanza de la religión católica e indica que a la jerarquía eclesiástica le corresponde señalar los contenidos de dicha enseñanza. Según este acuerdo, la disposición adicional segunda de la Ley Orgánica 8/2013, de 9 de diciembre, para la mejora de la calidad educativa establece que se incluirá la religión católica como área o materia en los niveles educativos que corresponda, que será de oferta obligatoria para los centros y de carácter voluntario para los alumnos.

Asimismo, dispone que la determinación del currículo y de los estándares de aprendizaje evaluables que permitan la comprobación del logro de los objetivos y la adquisición de las competencias correspondientes a la asignatura de Religión sea competencia de la autoridad religiosa. Las decisiones sobre utilización de libros de texto y materiales didácticos y, en su caso, la supervisión y aprobación 
de estos corresponden a la autoridad religiosa, según lo establecido en el acuerdo suscrito con el Estado español (Esteban, 2015a).

El Real Decreto 126/2014, de 28 de febrero, por el que se establece el currículo básico de la Educación Primaria, indica en su disposición adicional segunda que la determinación del currículo de la enseñanza de la religión católica y de las diferentes confesiones religiosas con las que el Estado español ha suscrito acuerdos de cooperación en materia educativa será competencia de la jerarquía eclesiástica y de las correspondientes autoridades religiosas.

El Real Decreto 1105/2014, de 26 de diciembre, por el que se establece el currículo básico de la ESO y del bachillerato, indica en su disposición adicional tercera que la determinación del currículo de la enseñanza de la religión católica y de las diferentes confesiones religiosas con las que el Estado español ha suscrito acuerdos de cooperación en materia educativa será competencia de la jerarquía eclesiástica y de las correspondientes autoridades religiosas.

De acuerdo con los preceptos indicados, la Conferencia Episcopal Española ha determinado los currículos de la enseñanza de la religión católica para la EP y la ESO (Resolución de 11 de febrero de 2015, de la Dirección General de Evaluación y Cooperación Territorial, por la que se publica el currículo de la enseñanza de Religión Católica de la Educación Primaria y de la Educación Secundaria Obligatoria). En las Jornadas Nacionales de Vicarios y Delegados de Enseñanza organizadas por la Conferencia Episcopal Española en febrero de 2014, se presentó un nuevo currículo de religión católica adaptado a la Ley Orgánica 8/2013, de 9 de diciembre, para la mejora de la calidad educativa. El nuevo currículo mantiene el concepto de competencias básicas (en ella se opta por la denominación competencias clave) y añade unas competencias específicas para el área de religión y moral católica en las etapas de EP, ESO y bachillerato. Junto con los contenidos y criterios de evaluación de cada curso, se introducen los estándares de aprendizaje evaluables que guardan relación con los criterios de evaluación y las competencias (Esteban, 2014).

En concreto, los estándares son especificaciones de los criterios de evaluación que permiten definir los resultados de los aprendizajes, y que concretan mediante acciones lo que el alumno debe saber y saber hacer en relación con cada asignatura; deben ser observables, medibles y evaluables, y permitir graduar el rendimiento o logro alcanzado, y tienen que contribuir y facilitar el diseño de pruebas estandarizadas y comparables. Para responder a un vacío presente en la anterior formulación del currículo, en cada una de las etapas se introducen unas orientaciones metodológicas didácticas, como lo indica el Real Decreto 126/2014, de 28 de febrero, por el que se establece el currículo básico de la Educación Primaria: 
"conjunto de estrategias, procedimientos y acciones organizadas y planificadas por el profesorado, de manera consciente y reflexiva, con la finalidad de posibilitar el aprendizaje del alumnado y el logro de los objetivos planteados" (Esteban, 2016).

En este sentido, la asignatura de Religión católica utilizará una metodología que respetará los siguientes principios:

- Reconocimiento del rol del docente: el docente es pieza clave en la elaboración e implementación de actividades de aula ajustadas al grupo concreto que está enseñando. Su formación resulta, por tanto, fundamental a la hora de garantizar el éxito del proceso de aprendizaje.

- Adaptación al ámbito emocional y cognitivo de los estudiantes respetando el desarrollo psicoevolutivo propio de cada etapa: esta atención permitirá combinar de manera adecuada lo concreto y lo abstracto, el trabajo individual y el grupal, lo manipulativo, lo experiencial y lo visual con los aspectos conceptuales.

- $\quad$ Respeto por los ritmos y estilos de aprendizaje de los estudiantes. No todos los estudiantes son iguales, no todos aprenden a la misma velocidad ni utilizan las mismas estrategias. La atención a la diversidad y el desarrollo de la inclusión comienza en la asunción de este principio fundamental.

- Consideración de la dimensión humanista: todos los aprendizajes estarán al servicio de la formación humana. La asignatura de Religión, desde su clave personalizadora, requiere que todo tipo de aprendizajes, instrumentales, cognitivos, actitudinales o socioafectivos no sean considerados fin en sí mismos, sino que estén al servicio de la formación integral del ser humano.

- Respeto por la curiosidad y las inquietudes de los estudiantes. Consideración de los intereses y de las expectativas de los estudiantes, así como de los conocimientos previos, de manera que se garantice un aprendizaje significativo.

- Seguimiento de los criterios de evaluación educativa. Para facilitar el cumplimiento de estos principios metodológicos, se aplicará una evaluación continua, global y formativa a lo largo del proceso de enseñanza-aprendizaje; y sumativa al final del proceso, de manera que se evalúe el nivel de logro alcanzado. La evaluación objetiva garantizará una valoración adecuada de la dedicación, del esfuerzo y del rendimiento de todos los estudiantes.

- Desarrollo del aprendizaje en equipo o cooperativo: el estudio y la reflexión del cristianismo, por su intrínseca dimensión comunitaria, es 
una asignatura adecuada para desarrollar el trabajo en equipo y el aprendizaje cooperativo.

- Utilización educativa de los recursos tecnológicos: la enseñanza de la religión promoverá la utilización de las tecnologías de la información y de la comunicación (TIC), no solo de una manera instrumental, que resulte útil al estudiante en la búsqueda de información o en la resolución de problemas planteados en la clase, sino procurando su integración en la vida del sujeto y su uso ético. Las redes sociales o las herramientas de construcción y manipulación de imágenes, por ejemplo, son instrumentos que permiten nuevas formas de expresión de la cultura y de la identidad personal que hay que aprender a dominar (Resolución de 11 de febrero de 2015, de la Dirección General de Evaluación y Cooperación Territorial, por la que se publica el currículo de la enseñanza de Religión Católica de la Educación Primaria y de la Educación Secundaria Obligatoria).

- Los contenidos del currículo se entienden como una síntesis de la fe cristiana: mantienen la estructura básica, aunque se resitúan algunos contenidos (Resolución de 11 de febrero de 2015, de la Dirección General de Evaluación y Cooperación Territorial, por la que se publica el currículo de la enseñanza de Religión Católica de la Educación Primaria y de la Educación Secundaria Obligatoria).

El desarrollo del currículo se estructura en cuatro grandes bloques que pretenden recoger el saber antropológico cristiano acumulado a lo largo de los siglos. Esos bloques parten del sentido religioso del hombre, continúan con el estudio de la Revelación: Dios se manifiesta al hombre y lo hace en una historia concreta, con personajes y situaciones que el alumnado debe conocer y que contribuirán a su comprensión del mundo. Dicha Revelación culmina en Jesucristo y el mensaje evangélico, centro del tercer bloque del currículo y eje vertebrador de la asignatura. Por último, se estudia la Iglesia como manifestación de la presencia continuada de Jesucristo en la historia. La enseñanza de la religión católica ilustra a los estudiantes sobre la identidad del cristianismo y la vida cristiana (Resolución de 11 de febrero de 2015, de la Dirección General de Evaluación y Cooperación Territorial, por la que se publica el currículo de la enseñanza de Religión Católica de la Educación Primaria y de la Educación Secundaria Obligatoria).

La estructura del currículo intenta poner de manifiesto la profunda unidad y armonía de la iniciativa creadora y salvífica de Dios. El primer bloque parte de los datos más evidentes: la constatación de la realidad de las cosas y de los seres 
vivos, de modo especial el hombre. Se nos impone su existencia como dato evidente. En un segundo paso, si la persona no se queda en el primer impacto o simple constatación de su existencia, tiene que reconocer que las cosas, los animales y el ser humano no se dan el ser a sí mismos. Luego, otro los hace ser, los llama a la vida y se la mantiene. Por ello, la realidad en cuanto tal es signo de Dios, habla de su existencia.

La iniciativa creadora de Dios tiene una finalidad: establecer una relación de amistad con el hombre. Es decir, Dios ha creado al ser humano para que sea feliz en relación con Él. Los relatos bíblicos de la Creación y del Paraíso ejemplifican bellamente la finalidad de la creación de la persona y del mundo entero para su servicio. De su origen de creación natural y de su llamada a participar en la amistad con Dios, surge su dignidad inviolable.

No obstante, el ser humano pretende apropiarse del don de Dios prescindiendo de Él. En esto consiste el pecado. Este rechazo de Dios tiene como consecuencia en el ser humano la imposibilidad de ser feliz. Dado que su naturaleza está hecha para el bien, su experiencia de mal y de límite le hace añorar la plenitud que él no puede darse por sí mismo y busca de algún modo restablecer la relación con Dios. Esta necesidad del bien, el deseo de infinito que caracteriza al ser humano, se expresa en las religiones como búsqueda del Misterio.

A esta búsqueda humana Dios responde manifestándose en la historia. Para ello, elige un hombre, Abraham, del que formará el pueblo de Israel, con quien establece una alianza en el monte Sinaí. A través de hechos y palabras, Dios irá dándose a conocer a los hombres de ese pueblo. Todo este acontecer histórico de la manifestación de Dios está recogido en los libros sagrados de la Biblia. En este conjunto de libros, no solo se recogen las diferentes intervenciones de Dios en la historia, sino también la enseñanza que comunica a su pueblo para que viva una vida santa; una sabiduría que influirá positivamente en la vida del pueblo de Israel $y$, con el tiempo, en el mundo entero.

1. La historia de Israel ejemplifica la traición y rebelión de los hombres ante la iniciativa amorosa de Dios y al mismo tiempo pone en evidencia la constante fidelidad divina. La promesa de un salvador se cumplirá en Cristo Jesús.

2. Jesús, el Hijo de Dios, se hace presente en la historia para llevar a cabo la misión encomendada por el Padre. En Jesucristo, se cumple el deseo de felicidad que el hombre descubre en su corazón.

3. Jesús no solo devela el misterio humano y lo lleva a su plenitud, sino que manifiesta el misterio de Dios, nos hace conocer que el verdadero Dios es comunión: Dios Uno y Trino. 
4. Aquellos que participan de la vida de Cristo forman la Iglesia, que es la gran familia de Dios. Continuamente generada por la acción de Jesucristo a través de los sacramentos, se pone en el mundo como inicio de un mundo nuevo, de una cultura nueva. La Iglesia es la prolongación de Cristo en el tiempo y el espacio. Solo en ella la persona humana se encuentra con el Jesucristo vivo.

5. La vida eclesial es alimentada y servida mediante los diferentes sacramentos instituidos por Jesucristo, está ritmada por los tiempos litúrgicos, se expresa en la oración comunitaria y la caridad, fructifica en la generación de una civilización del amor.

Estos cinco bloques que componen la asignatura de Religión católica incluyen conceptos, procedimientos y actitudes, que permiten el conocimiento de sí mismo, de la realidad y de los problemas que esta plantea. Por ello, los contenidos generales de la asignatura contribuyen a la consecución de los objetivos propuestos para las diferentes etapas.

Este currículo se vale de los elementos cristianos presentes en el entorno del alumnado, las imágenes y los símbolos, el lenguaje y otros recursos, para la comprensión de la religiosidad propia de cada etapa evolutiva. Se desarrolla así la competencia en comunicación lingüística, que se sirve del lenguaje que conforma la cultura y tradición que se transmite de una a otra generación. Así, el lenguaje bíblico y su riqueza de expresión y simbología, el lenguaje doctrinal y su precisión conceptual, analítica y argumental y el lenguaje litúrgico y su cercanía al lenguaje de los símbolos del pueblo cristiano, ayudarán al desarrollo de esta competencia en los estudiantes. Sin olvidar la singularidad que esta asignatura aporta a la dimensión de escucha de la comunicación.

Asimismo, la enseñanza escolar de la religión católica favorece el desarrollo de la responsabilidad personal y social y de las demás virtudes cívicas, para el bien común de la sociedad, y así contribuir a la adquisición de las competencias sociales y cívicas. Esta educación de la dimensión moral y social de la persona favorecerá la maduración de una corresponsabilidad y el ejercicio de la solidaridad, de la libertad, de la justicia y de la caridad.

Por otra parte, la religión católica aporta a la competencia cultural y artística el significado y la valoración crítica de tantas obras de nuestro entorno, motivando el aprecio por la propia cultura y la estima adecuada de otras tradiciones culturales y religiosas. La cultura y la historia occidental, la propia historia, no pueden ser comprendidas y asumidas si se prescinde del hecho religioso presente siempre en la historia cultural de los pueblos. De igual modo, la expresión 
artística de la fe sigue colaborando en la actualidad al enriquecimiento de nuestro patrimonio cultural.

La competencia para la autonomía e iniciativa personal se desarrolla en el estudiante partiendo del verdadero conocimiento de sí mismo, de sus potencialidades, de su dignidad y de su sentido. La formación religiosa católica aporta a dicha competencia una cosmovisión que da sentido a la vida y, por tanto, a la cultura y a la identidad de la persona humana. Una cosmovisión que hace posible la formación integral del estudiante frente a visiones parciales.

\section{Contribución del área de religión católica al desarrollo de las competencias clave}

\subsection{Competencia en comunicación lingüística}

La enseñanza religiosa católica aporta elementos básicos en cuanto al logro de la competencia en comunicación lingüística, pues se sirve del lenguaje académico, de los lenguajes que conforman la cultura que se transmite en el área de religión, así como de los lenguajes de la propia enseñanza religiosa.

El diálogo de la fe con la cultura contribuye a la competencia en comunicación lingüística, en la medida en que exige ejercitarse en la escucha de la palabra de Dios, en los diversos modos de comunicación que la acción de Dios sobre el hombre ha utilizado. Su revelación es rica en distintos lenguajes. Así, el lenguaje bíblico y su riqueza de expresión y simbología, el lenguaje doctrinal y su precisión conceptual, analítica y argumental, el lenguaje litúrgico y su cercanía al lenguaje de los símbolos del pueblo cristiano, el lenguaje, en fin, testimonial que hace posible la transmisión vital de lo conocido.

\subsection{Aprender a aprender}

La enseñanza religiosa contribuye positivamente al desarrollo de la competencia de aprender a aprender en el estudio y en la reflexión del mensaje cristiano, facilitando el impulso del trabajo en equipo por su intrínseco sentido comunitario, proponiendo no solo una propuesta consensuada de valores y actitudes, sino un marco de referencia aceptado voluntariamente según sus convicciones, que ha de ser crisol en la búsqueda de la verdad y del bien. 


\subsection{Competencias sociales y cívicas}

Con relación a las competencias sociales y cívicas, la enseñanza religiosa católica aporta la fundamentación y jerarquización de los valores y de las virtudes que contribuyen a educar la dimensión moral y social de la personalidad del alumno, en orden a hacer posible la maduración en la corresponsabilidad, el ejercicio de la solidaridad, de la libertad, de la justicia y de la caridad. Todo ello como expresión coherente del conocimiento de Dios revelado en Jesucristo. Ello conlleva mejorar las relaciones interpersonales basadas en principios y valores que emanan de la persona de Cristo y ayuda, en consecuencia, a afrontar las situaciones de conflicto mediante el diálogo, el perdón y la misericordia, valores genuinamente cristianos. En lo más profundo del ser cristiano, surge el gran valor de la fraternidad universal. De ahí que las mínimas exigencias éticas de convivencia, participación y respeto a la diversidad sean consecuencias de la fe cristiana.

\subsection{Sentido de iniciativa y espíritu emprendedor}

La competencia para el sentido de iniciativa y de espíritu emprendedor no podrá realizarse en el alumno si no comienza ya a adiestrarse en el conocimiento de sí mismo, en su ser más profundo, en sus potencialidades, en su dignidad y en su sentido.

La formación religiosa católica aporta a dicha competencia una cosmovisión que da sentido a la vida y, por tanto, al sentido de la cultura y de la identidad misma de la persona humana. Una cosmovisión que hace posible la formación integral del alumno frente a visiones parciales y determinantes de la libertad propia. En síntesis, la enseñanza religiosa católica no se reduce a una enseñanza de valores, sino que se dirige a la persona concreta en sus raíces, en sus posibilidades humanas y, sobre todo, se dirige al ser humano en su finalidad trascendente. Todo ello conlleva el ofrecimiento del Evangelio de salvación de Jesucristo, para que, una vez conocido, surja la humanidad nueva hecha de hombres nuevos conforme al designio de Dios.

\subsection{Conciencia y expresiones culturales}

La religión y moral católica aportan una valoración crítica de la cultura a la luz del Evangelio, motivando al mismo tiempo el aprecio de la propia cultura y la estima adecuada de otras tradiciones culturales y religiosas. La cultura y la historia europea occidental, y la propia historia y cultura española, no pueden ser 
comprendidas y asumidas si se prescinde del hecho religioso presente siempre en la historia cultural de los pueblos.

\subsection{Contribución del área de religión católica al desarrollo de los contenidos procedimentales y actitudinales}

La enseñanza religiosa católica se estructura a partir de cuatro dimensiones que fundamentan las competencias específicas de la enseñanza religiosa católica: la dimensión cultural e histórica, la dimensión humanizadora, la dimensión éticomoral y la dimensión epistemológica. Estas dimensiones aportan, a su vez, elementos con referencia a las competencias básicas, ya analizadas, y orientan y clarifican las competencias y capacidades específicas del área de religión católica.

- La dimensión cultural e histórica está presente en la enseñanza religiosa, dado que el patrimonio cultural, histórico y antropológico-axiológico que gran parte de las sociedades reciben del pasado está vertebrado por contenidos religiosos. En este sentido, la religión católica ha dado sus frutos en el arte, en los sistemas de significación moral, en la creación popular y en la acción social. El alumno no solo va a conocer, sino que podrá comprender y asumir los valores que conlleva el conocimiento del hecho religioso en su expresión artística, cultural y estética, teológica y vivencial.

- La dimensión ético-moral explicita las exigencias morales que conlleva el mensaje cristiano. En la religión católica, se ofrece una determinada manera de ver la vida, en cuya base se encuentra un concepto de hombre, un núcleo referencial de ideas y creencias, y la propuesta de una escala de principios y valores. La enseñanza religiosa católica expone, fundamenta y jerarquiza los valores y virtudes capaces de educar la dimensión moral y social de la personalidad del alumno, en orden a hacer posible la maduración en la responsabilidad, el ejercicio de la solidaridad y de la caridad. Todo ello como expresión coherente del conocimiento de Dios revelado en Jesucristo. Con ello estamos fundamentando uno de los valores básicos, su dignidad como ser humano, como hijo de Dios. El sistema educativo no puede tener como objetivo reproducir sin más el modelo de sociedad existente. Habrá de disponer a sus alumnos para que puedan abordar críticamente esa sociedad e intervenir en ella para cambiarla o modificarla.

- Para ello, la dimensión humanizadora en la enseñanza religiosa católica faculta al alumno para dar respuesta a sus interrogantes más radicales, 
haciendo posible, a su vez, la formación de hombres y mujeres conscientes, críticos, libres y creadores. El alumno necesita, ya en estas edades, especialmente motivaciones para amar, para construir la personalidad más humana, para ilusionarse en proyectos de vida altruista y desinteresada. El testimonio de hombres y mujeres santos en toda la historia constituye un referente continuo para la autoasimilación de los valores más genuinamente cristianos.

- La dimensión epistemológica se presenta en el ámbito escolar, en su estructura disciplinar, con el carácter científico con el que se abordan las ciencias de la religión y la teología. Sus contenidos son saberes con una fundamentación y una metodología científica propia, implantados con rigor y tradición en nuestro entorno cultural. Su estatuto epistemológico original entra en el ámbito educativo en confrontación y diálogo con aquellos otros tipos de saberes y racionalidad que operan en la escuela.

- La síntesis teológica es una dimensión básica y, a su vez, el objetivo general que irá desarrollándose y aplicándose en cada una de las etapas y de los cursos con referencia a cada uno de los núcleos temáticos que conforman la síntesis teológica: el fenómeno religioso, la cultura y la historia de la religión, la Biblia, Dios Padre, Jesucristo, el Espíritu Santo, la Iglesia, los sacramentos, la liturgia, la vida cristiana, la moral y los valores, la Virgen María, la escatología, etc.

A partir de estas dimensiones, concretamos y desarrollamos las competencias específicas de la materia de Religión y Moral Católica, la competencia cultural e histórica, la competencia humanizadora, la competencia ético-moral, la competencia epistemológica y la competencia de sentido trascendente, contribuyendo, a su vez, a las competencias básicas comunes a todas las materias del currículo de los alumnos.

Conforme a las competencias establecidas en el citado acuerdo internacional y reconocido en la disposición adicional segunda de la Ley Orgánica 8/2013, de 9 de diciembre, para la mejora de la calidad educativa, corresponde a la Conferencia Episcopal Española fijar el currículo del área de religión y moral católica.

\section{Conclusión}

La religión ha sido desde décadas un elemento esencial en la enseñanza y en la formación de los distintos sistemas educativos españoles y de países europeos, pues ha sido considerada como un pilar básico en el bagaje cultural y social de 
cada país, como un instrumento de vital importancia en la transmisión de valores. Por ese motivo, no debemos dejar de ser conscientes del papel tan relevante que la religión ocupa en la sociedad, ya que esta marca y orienta los modelos y las formas de vida de la mayoría de los ciudadanos. Tal responsabilidad también se ejercita en el derecho a elegir la escuela que garantice una educación conforme a los propios principios religiosos y morales.

De aquí que la propuesta de excluir de los currículos escolares la enseñanza religiosa obedece a un proyecto de sociedad, ajeno a los sistemas religiosos sostenido sobre los principios de la soberanía de los Estados, ya que la enseñanza de la religión (católica, evangélica, judía e islámica) está garantizada como un derecho por los diversos acuerdos que el Estado español tiene firmados tanto con la Iglesia católica (que tienen naturaleza jurídica de tratados internacionales) como con las federaciones de entidades evangélicas, judías y musulmanas. Se garantiza el derecho a recibirla.

En este sentido, los alumnos deben ser formados en materia religiosa, con la finalidad de dotarlos de una formación integral que haga de ellos personas independientes y con unos ideales propios que les permitan emitir sus propios juicios y optar por el modo de vida religiosa que ellos elijan. La escuela como institución socializadora y educadora debe también facilitar una educación en materia religiosa que inicie en los aspectos más importantes de la religión que vaya a formar parte de la vida futura de los actores vivos del proceso educativo, los alumnos.

\section{Referencias}

Cano Ruiz, I. (2014). La enseñanza de la religión en la escuela pública: Actas del VI Simposio Internacional de Derecho Concordatario. Alcalá de Henares, 16-18 de octubre de 2013. Granada, España: Comares.

Díez de Velasco, F. (2016). La enseñanza de las religiones en la escuela en España: avatares del modelo de aula segregada. Historia y Memoria de la Educación, 4, 277-306. Doi: https://doi.org/10.5944/hme.4.2016.15484

Esteban Garcés, C. (2014). Para comprender la LOMCE: análisis y comentarios de la Ley para el profesorado de Religión. Madrid, España: SM.

Esteban Garcés, C. (2015a). La asignatura de Religión en el sistema educativo LOMCE. Madrid, España: Boadilla del Monte.

Esteban Garcés, C. (2015b). Pedagogía de la religión: nuevo currículum de religión católica para la LOMCE. Religión y Escuela: la Revista del Profesorado de Religión, 288, 26-29. 
Esteban Garcés, C. (2016). Otra reforma educativa en España y un nuevo currículo de religión católica. Sinite: Revista de Pedagogía Religiosa, 57(172), 299-360.

Ley 24/1992, de 10 de noviembre, por la que se aprueba el Acuerdo de Cooperación del Estado con la Federación de Entidades Religiosas Evangélicas de España.

Ley 25/1992, de 10 de noviembre, por la que se aprueba el Acuerdo de Cooperación del Estado con la Federación de Comunidades Israelitas de España.

Ley 26/1992, de 10 de noviembre, por la que se aprueba el Acuerdo de Cooperación del Estado con la Comisión Islámica de España.

Ley General de Educación y Financiamiento de la Reforma Educativa (LGE) de 4 de agosto de 1970.

Ley Orgánica 2/2006, de 3 de mayo, de Educación.

Ley Orgánica 8/2013, de 9 de diciembre, para la mejora de la calidad educativa.

Melero Martínez, J. M. (2006). ¿La religión en la escuela? Ensayos, 21, 79-86.

Panizo, A. y Arce, R. de (2012). Religión y sistema educativo español. Revista General de Derecho Canónico y Derecho Eclesiástico del Estado, 30, 1-51.

Real Decreto 126/2014, de 28 de febrero, por el que se establece el currículo básico de la Educación Primaria.

Real Decreto 1105/2014, de 26 de diciembre, por el que se establece el currículo básico de la Educación Secundaria Obligatoria y del Bachillerato.

Resolución de 11 de febrero de 2015, de la Dirección General de Evaluación y Cooperación Territorial, por la que se publica el currículo de la enseñanza de Religión Católica de la Educación Primaria y de la Educación Secundaria Obligatoria.

Víboras García, E. Á. (2014). Comparativa de la enseñanza de la religión en los países europeos. Recuperado de http://www.anpeandalucia.org/userfiles/file/pdfs/articulo_eviboras_0314.pdf

Yzaguirre, F. (2002). La asignatura de Religión Católica en el sistema educativo público español. Recuperado de https://laicismo.org/la-asignatura-de-religion -catolica-en-el-sistema-educativo-publico-espanol/ 